Elsevier

HRR 00961

\title{
Three molecular steps of aminoglycoside ototoxicity demonstrated in outer hair cells
}

\author{
Sally E. Williams ${ }^{1}$, Hans-P. Zenner ${ }^{2}$ and Jochen Schacht ${ }^{1}$ \\ ${ }^{\prime}$ Kresge Hearing Research Institute, University of Michigan, Ann Arbor, U.S.A. and ${ }^{2}$ Universitätsklinik und Poliklinik \\ für HNO-Kranke Kopfklinikum, D-8700 Würzburg, F.R.G.
}

(Received 20 January 1987; accepted 17 April 1987)

\begin{abstract}
Previously postulated molecular mechanisms of aminoglycoside ototoxicity were investigated in outer hair cells in vitro. Cells were isolated by microdissection from the organ of Corti of the guinea pig and maintained in Hank's balanced salt solution. (1) Approx. 100 cells (the standard number per assay) bound $432 \pm 198$ pmol calcium as determined with ${ }^{45} \mathrm{Ca}^{2+}(1.2 \mathrm{mM}) .1 \mathrm{mM}$ neomycin or gentamicin lowered this value by $28 \%$ and $45 \%$, respectively. (2) Binding of radiolabeled gentamicin ( 28 fmol per 100 cells at $0.1 \mu \mathrm{M}$ gentamicin) was reduced by $55 \%$ by $1 \mathrm{mM}$ neomycin or spermine. Washing with an excess of unlabeled gentamicin displaced only $60 \%$ of the drug, the remainder being tightly bound to a less accessible compartment. Incubation at low temperature essentially abolished gentamicin uptake. (3) Phospholipids were labeled with $l^{32}$ PJorthophosphate which was mostly incorporated into phosphatidylinositol 4,5-bisphosphate ( $\left.\mathrm{PIP}_{2}\right)$, phosphatidylinositol 4-phosphate, phosphatidylinositol, and phosphatidic acid. When the lipids were chromatographed over immobilized gentamicin PIP $\mathbf{P}_{2}$, in contrast to other lipids, was strongly retained. These results are compatible with the following actions of aminoglycosides in outer hair cells: (1) competition with calcium; (2) energy-dependent uptake competitive with polyamines; and (3) binding to the phospholipid $\mathrm{PIP}_{2}$.
\end{abstract}

Ototoxicity; Hair cell; Aminoglycoside antibiotic; Molecular mechanism

\section{Introduction}

Recently, this laboratory proposed a molecular model for aminoglycoside ototoxicity (Schacht, 1986). Based on evidence from in vivo and in vitro studies, the model comprised several sequential steps: (1) reversible binding of the aminoglycoside to the plasma membrane in competition with calcium; (2) energy-dependent uptake of the drug with similarities to polyamine transport; (3) intracellular binding to PIP $_{2}$, a physiologically important lipid involved in the inositol phosphate second messenger system.

Evidence for these individual steps had been obtained from in vivo and in vitro studies in a variety of tissues. Competition of aminoglycosides with calcium had been shown directly in binding studies in inner ear tissues of the guinea pig (Orsulakova et al., 1976) as well as indirectly in

Correspondence to: J. Schacht, Kresge Hearing Research Institute, University of Michigan, Ann Arbor, MI 48109. U.S.A. studies of drug effects on the cochlear microphonic potential (Takada and Schacht, 1982). The occupation by the drugs of at least two separate cellular compartments in the course of their toxic actions was independently concluded from their pharmacokinetic behavior in the cochlea of the rat (Tran Ba Huy et al., 1986) and their dual actions on the cochlear microphonics during perilymphatic perfusions in the guinea pig (Takada and Schacht, 1982; Takada et al., 1985). Uptake of gentamicin was determined in the developing inner ear of the mouse (Schacht and Van De Water, 1986) and further characterized in the crista ampullaris of the guinea pig (Williams et al., 1987). Inhibition of PIP $P_{2}$ metabolism by aminoglycosides had been observed in vivo and in vitro (Schacht, 1976; Tachibana et al., 1983) and physicochemical parameters of the drug/lipid interactions were measured in membrane models (Lodhi et al., 1979; Wang et al., 1984b). Since there was an excellent correlation between the ototoxic potential of various aminoglycosides and their ability to disturb 
the structure of $\mathrm{PIP}_{2}$-containing membranes (Wang ct al., 1984a; Au ct al., 1986a, b) this interaction was considered a critical determinant of ototoxicity.

While the cumulative evidence was highly supportive of the proposed scheme none of the studies had been able to relate the observations directly to hair cells. Cochleotoxic aminoglycosides preferentially - albeit not exclusively - damage the outer hair cells as extensively documented by histopathological observations (Hawkins, 1976). A crucial test, therefore, of any hypothesis of aminoglycoside action should be its examination at the level of the hair cells. Recent improvements in the methods to isolate live mammalian outer hair cells (Brownell et al., 1985; Zenner et al., 1985) now make such experiments feasible. The present study investigates each of the three proposed steps of our hypothesis in isolated outer hair cells in vitro.

\section{Materials and Methods}

Isolated hair cells were prepared essentially as described previously (Zenner et al., 1985; Zajic and Schacht, 1987). Pigmented guinea pigs were ancsthetized with ether and perfused through the heart with saline for $5 \mathrm{~min}$ to flush cochlear blood vessels. After decapitation each bulla was removed and the cochlea exposed. Surface preparations from the two apical turns were placed in a $60 \times 15$ mm Petri dish (Falcon 3002; Becton-Dickinson, Oxnard, CA) with Hank's balanced salt solution (HBSS), $300 \mathrm{mOsm}$, containing $1 \mathrm{mg}$ collagenase /ml (type IV, Sigma Chemical Co., St. Louis, MO). After 10 min the tissue was transferred into fresh HBSS and the hair cells were teased from the basilar membrane with fine tungsten wires. Isolated hair cells were removed to a second Petri dish and excess media and contaminating material such as supporting cells and red blood cells drawn off.

The binding reactions were started by adding the radioactive material, $0.1 \mu \mathrm{Ci}(1.2 \mathrm{mM}){ }^{45} \mathrm{CaCl}_{2}$ (New England Nuclear, Boston, MA) or $0.1 \mu \mathrm{Ci}$ $(0.125 \mu \mathrm{M}){ }^{125}$ I-labeled gentamicin (American Bioclinical, Portland, OR; $20 \mathrm{Ci} / \mathrm{mmol}$ ), to the hair cells in HBSS, final volume $40 \mu$ l. In competition experiments, the competitor was added $5 \mathrm{~min}$ prior to the radiolabeled material. To end the incubation the hair cells were layered over $150 \mu \mathrm{l}$ of a $300 \mathrm{mM}$ sucrose/HBSS mixture $(1: 4, v / \mathrm{v}$; adjusted to $300 \mathrm{mOsm}$ ) in polypropylene tubes $(5 \times 20 \mathrm{~mm})$ and sedimented at $180 \times g$ for $45 \mathrm{~s}$. The top two thirds of the gradient were removed followed by the lowermost $15 \mu \mathrm{l}$ containing the hair cells. Radioactivity in these two and the remaining fractions was determined by liquid scintillation counting. Blanks without cells were assayed simultaneously. Counts in the hair cell fraction were expressed as a percentage of the total radioactive material minus the blank values.

For lipid labeling, outer hair cells were incubated for $1 \mathrm{~h}$ at room temperature in $75 \mu \mathrm{l}$ of HBSS with 200 to $500 \mu \mathrm{Ci}\left[{ }^{32}\right.$ P]orthophosphate. The reaction was terminated by the transfer of the assay into $0.3 \mathrm{ml}$ of chloroform/methanol $(1: 2$, by vol.) and lipids were extracted as described previously (Schacht, 1979). For the analysis of gentamicin : lipid binding, dried extracts from four incubations were resuspended in $50 \mathrm{mM}$ ammonium acetate in chloroform/methanol/water ( $3: 6: 1$, by vol.) and chromatographed over a column $(0.2 \mathrm{ml})$ of gentamicin coupled to glass beads in a procedure analogous to the chromatography over immobilized neomycin (Schacht, 1978). After applying the lipids the column was washed with $3.6 \mathrm{ml}$ of $50 \mathrm{mM}$ ammonium acetate in chloroform/methanol/water (3:6:1, by vol.), followed by $1.2 \mathrm{ml}$ each of $75 \mathrm{mM}, 100 \mathrm{mM}$, and 600 $\mathrm{mM}$ ammonium acetate in the same solvent. Lipids were extracted from the eluates and separated on thin layer chromatography plates (Silica Gel 60 , Merck, Darmstadt) in chloroform/methanol/14 $\mathrm{N}$ ammonium hydroxide/water $(45: 45: 3.5: 11$, by vol.). Plates were exposed to X-ray film to locate ${ }^{32} \mathrm{P}$-labeled lipids.

The statistical significance of the results was determined by a one-way ANOVA.

\section{Results}

More than 200 cells were isolated from one cochlea and approximately one hundred used in each assay. Contaminating cellular debris and red blood cells were largely eliminated by the transfer of hair cells into fresh HBSS after their isolation (Fig. 1A). Furthermore, the cardiac pefusion prior 

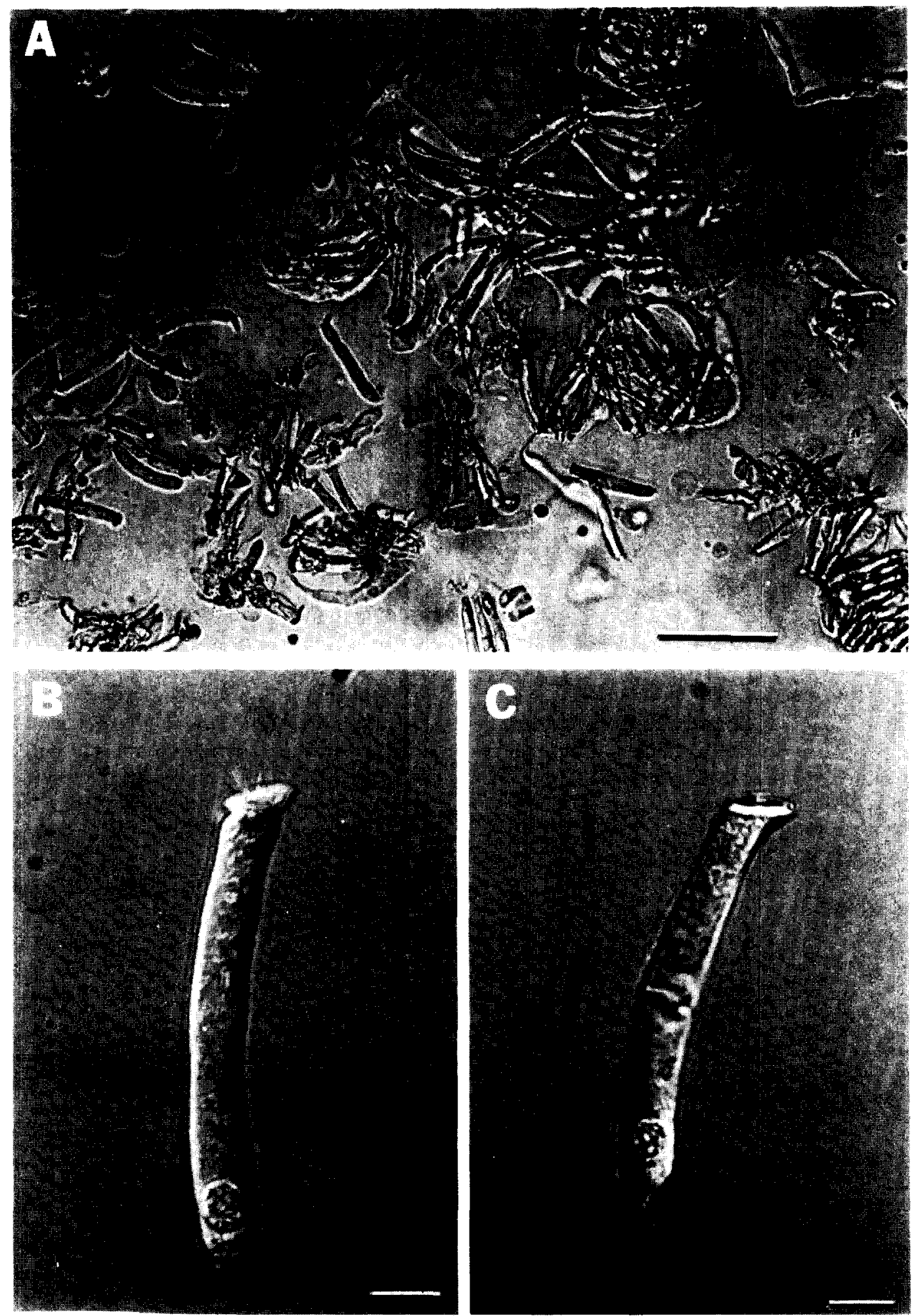

Fig. 1. Isolated outer hair cells of the guinea pig. (A) Cells harvested for incubations. Both individual cells as well as hair cell clusters were used. Calibration: $100 \mu \mathrm{m}$. (B) Typical individual hair cell before incubation and centrifugation. Note cylindrical shape without swelling, absence of granulation from cytoplasm, and low position of the nucleus. Calibration: $10 \mu \mathrm{m}$. (C) Typical individual hair cell after incubation and centrifugation. Although the cell is bent it essentially shows the features of a viable hair cell. Calibration: $10 \mu \mathrm{m}$. 
to killing the animal reduced the number of red blood cells otherwise present by about $75 \%$. The remaining contaminants, as detailed later, did not interfere with the assays.

The morphology of the hair cells was judged before the incubations and any batch of cells not meeting the criteria of morphological quality was discarded. These criteria were (Zajic and Schacht, 1987): cylindrical shape of the cells without distortions; low position of nucleus; cytoplasm devoid of granulation and Brownian motion (Fig. 1B). Preliminary incubations were examined microscopically to assure that the cells remained intact through all procedures (Fig. 1C). Excessive mechanical manipulation, elevated temperature ( $>$ room temperature), and high centrifugal forces were detrimental to the preservation of hair cells. Conditions were modified until they allowed the survival of intact cells.

\section{Calcium binding to hair cells}

Approximately 100 isolated hair cells bound $432 \pm 198 \mathrm{pmol} \mathrm{Ca}^{2+}$ when incubated in HBSS containing $1.2 \mathrm{mM} \mathrm{Ca}^{2+}$ (Table I). There was no apparent difference in the amount of calcium bound after $5 \mathrm{~min}$ or $30 \mathrm{~min}$. Blanks without hair cells always had measurable radioactivity but the assay conditions were designed such that the labeling of the hair cell fraction was at least 3 -fold higher $(P<0.001)$.

Both neomycin and gentamicin effectively com-

\section{TABLE I}

\section{CALCIUM BINDING TO ISOLATED OUTER HAIR CELLS}

Approximately 100 hair cells were incubated with $0.1 \mu \mathrm{Ci}(1.2$ $\mathrm{mM}){ }^{45} \mathrm{CaCl}_{2}$ in $\mathrm{HBSS}$ for $5 \mathrm{~min}$ at room temperature as described in Methods. When indicated, $1 \mathrm{mM}$ neomycin or gentamicin were added. All values are means $\pm S . D$. and are corrected for blank values obtained from incubations without hair cells.

\begin{tabular}{lll}
\hline Addition & $\begin{array}{l}\text { Calcium bound } \\
\text { (pmol) }\end{array}$ & $n$ \\
\hline No drug added & $432 \pm 198$ & $17^{*}$ \\
Neomycin & $313 \pm 166$ & $12^{+}$ \\
Gentamicin & $238 \pm 104$ & $5^{++}$ \\
\hline
\end{tabular}

* Differs from blank without hair cells, $P<0.001$.

+ Differs from incubation without drug, $P=0.03$

${ }^{++}$Differs from incubation without drug, $P<0.001$. peted with calcium. At approximately equimolar concentrations ( $1 \mathrm{mM})$ to calcium they displaced $28 \%$ and $45 \%$ of the bound radioactivity, respectively. Neither in these acute experiments nor in the gentamicin binding assay did the aminoglycosides affect the morphology of the cells.

\section{Gentamicin binding to hair cells}

Binding was assayed at $0.125 \mu \mathrm{M}{ }^{125}$ I-labeled gentamicin in HBSS, i.e. in the presence of 1.2 mM calcium. ${ }^{125}$ I-labeled gentamicin is a convenient and valid substitute for the native drug (Williams et al., 1987) since aminoglycosides are difficult to obtain with other radiolabels in sufficiently high purity or specific radioactivity. Hair cells bound $27.9 \pm 18 \mathrm{fmol}$ of drug, a value again significantly higher $(P<0.001)$ than the blanks (Table II). More than $50 \%$ of the gentamicin was displaced by the addition of neomycin or the polyamine spermine.

Two experiments were designed to test the probable cellular distribution of the drug. When labeled hair cells were centrifuged through sucrose/HBSS containing $10 \mathrm{mM}$ unlabeled gentamicin the bound radioactivity was reduced by only $61 \%$ indicating an easily exchangeable pool of gentamicin and a more tightly bound fraction. When the temperature of the incubation and the subsequent centrifugation was lowered to

\section{TABLE II}

\section{GENTAMICIN BINDING TO ISOLATED OUTER HAIR CELLS}

Approximately 100 hair cells were incubated with $0.1 \mu \mathrm{Cl}$ $(0.125 \mu \mathrm{M}){ }^{125}$ I-labeled gentamicin in HBSS for $5 \mathrm{~min}$ at room temperature as described in Methods. Neomycin and spermine, when indicated, were added at $1 \mathrm{mM}$ concentrations. Gentamicin 'wash' indicates centrifugation of cells through 10 $\mathrm{mM}$ unlabeled gentamicin as described in Results. All values are means \pm S.D. and are corrected for blank values obtained from incubations without hair cells.

\begin{tabular}{llc}
\hline Condition & \multicolumn{1}{l}{$\begin{array}{l}\text { Gentamicin bound } \\
\text { (fmol) }\end{array}$} & $n$ \\
\hline Control & $27.9 \pm 18.0$ & $20^{*}$ \\
Neomycin added & $12.3 \pm 5.7$ & $5^{+}$ \\
Sperminc added & $12.6 \pm 6.3$ & $5^{+}$ \\
Gentamicin 'wash' & $10.8 \pm 9.6$ & $4^{+}$ \\
Temperature, $0-4^{\circ} \mathrm{C}$ & $1.5 \pm 1.5$ & $3{ }^{++}$ \\
\hline
\end{tabular}

* Differs from blank without hair cells, $P<0.001$.

+ Differs from control, $0.015<P<0.022$.

+* Differs from control, $P=0.001$ 
$0-4^{\circ} \mathrm{C}$ in order to reduce the metabolic activity of the cells the gentamicin content of hair cells was only $5 \%$ of its control, a value not significantly different from assay blanks.

\section{Lipid labeling}

The presence of phosphoinositides in outer hair cells was established in a series of six experiments. After incubation of hair cells with $\left[{ }^{32}\right.$ P]orthophos-

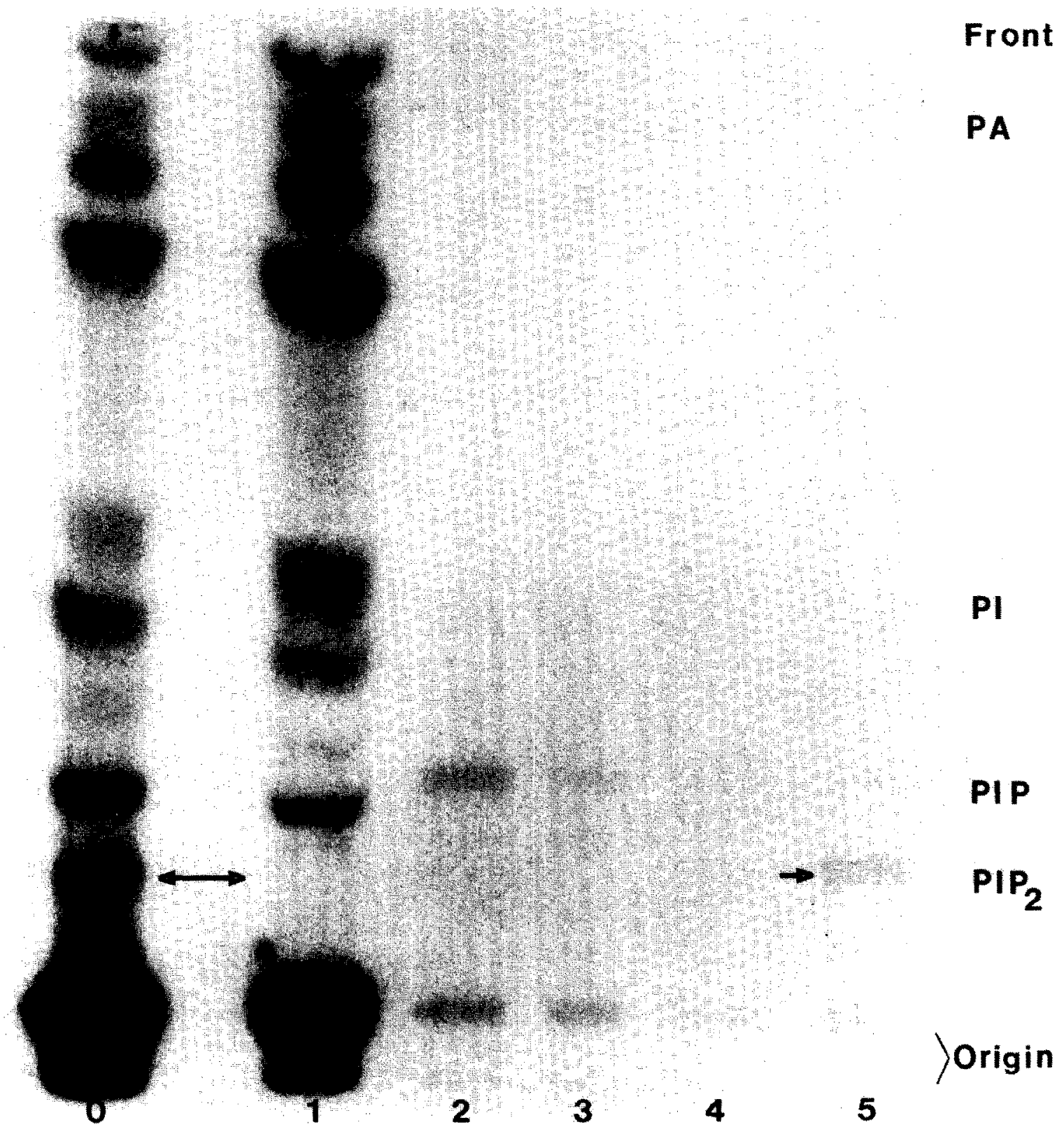

Fig. 2. Binding of PIP to immobilized gentamicin. Phospholipids of outer hair cells were labeled with [ ${ }^{32}$ Plorthophosphate and chromatographed on immobilized gentamicin as described in Methods. Shown here is the radioautographic localization of ${ }^{32} \mathrm{P}-\mathrm{labeled}$ lipids after thin layer chromatography. Lane 0 is an aliquot of the labeled lipids before application to the gentamicin column (starting material). Lanes $1-5$ are the fractions eluted from the column with increasing concentrations of ammonium acetate in chloroform/methanol/water $(3 ; 6: 1$, by vol.): lane 1 and $2,50 \mathrm{mM}$ : lane $3,75 \mathrm{mM}$; lane $4,100 \mathrm{mM}$; and lane $5,600 \mathrm{mM}$ ammonium acetate. Note the retention of $\mathrm{PIP}_{2}$ by gentamicin and its elution in fraction 5 . 
phate for $1 \mathrm{~h}$ at room temperature phospholipids were clearly labeled. Thin layer chromatography after the extraction of the cells showed the presence of several compounds which were identified by their $R_{\mathrm{f}}$ value and comparison to authentic lipids. All lipids of the phosphoinositide pathway were highly labeled: phosphatidylinositol 4,5-bisphosphate $\left(\mathrm{PIP}_{2}\right)$, phosphatidylinositol phosphate (PIP), phosphatidylinositol (PI) and phosphatidic acid (PA) (Fig. 2, lane 0). Other ${ }^{32}$ P-labeled lipids evident in this separation include phosphatidylcholine and phosphatidylethanolamine. The major band of radioactivity near the origin was also present in blank incubations and represents a contaminant in the $\left[{ }^{32} \mathrm{P}\right]$-orthophosphate or an artifact of the procedure.

\section{Binding of $\mathrm{PIP}_{2}$ to gentamicin}

Column chromatography on gentamicin was made possible by coupling the drug to glass beads as an immobile support thus allowing elution procedures without loss of the otherwise soluble gentamicin. The procedure was developed in a series of preliminary studies utilizing labeled lipids from brain or kidney and then applied to lipids obtained from outer hair cells. Lipid extracts from several incubations were pooled and loaded on the column. Two separate experiments with hair cell lipids yielded essentially identical results. Washing of the column with solvents of increasing ionic strength displaced the bound materials according to their binding affinity to gentamicin. Of the lipids applied in the starting solvent containing 50 mM ammonium acetate (Fig. 2, lane 0) none were retained by the gentamicin except $\mathrm{PIP}_{2}$ and a small fraction of the PIP (Fig. 2, lane 1). The latter was only slightly retarded (Fig. 2, lane 2) while further elution of the column did not detach $\mathrm{PIP}_{2}$ until the concentration of salt in the solvent was raised to $600 \mathrm{mM}$ (Fig. 2, lane 5).

\section{Controls}

In addition to processing blanks without hair cells along with each assay the possible contributions of cellular debris and red blood cells to the results was also directly assessed. For example, binding studies were performed with an amount of red blood cells that was estimated to be the maximal contamination in a hair cell preparation (see Fig. 1A). The radioactivity recorded did not significantly exceed that of the blanks.

Contributions to lipid labeling by contaminating supporting cells and other tissue was likewise determined by assaying an aliquot of the dissecting medium remaining after the removal of hair cells. Faint bands of radioactivity were frequently seen. On one occasion, strongly labeled lipids that were ascribed to bacterial contamination were evident. The pattern of bacterial ${ }^{32} \mathrm{P}$ labeled lipids is, however, unambiguously different in containing lipids not prominent in hair cells, such as cardiolipin. It should also be noted that bacteria do not contain PIP or PIP .

\section{Discussion}

The salient point of this study is that it provides evidence in outer hair cells compatible with three previously documented biochemical actions of gentamycin: (1) competition with calcium, (2) binding and uptake into cells, and (3) strong affinity for the lipid PIP $_{2}$.

Both gentamicin and neomycin displace calcium from outer hair cells. Calcium is an important cation in the control of membrane stability as well as excitation in hair cells (Hudspeth, 1985) and an actin-mediated slow motility of outer hair cells also depends on calcium (Flock et al., 1986; Zenner, 1986). While the precise site of the aminoglycoside/calcium interaction remains to be established, at least part of this competition should occur at the plasma membrane and thus may represent the acute effects (or parts thereof) of the drug as we have pointed out previously (Takada and Schacht, 1982; Schacht, 1986). The competition between aminoglycosides and calcium may, however, include intracellular actions if we assume that the radioactive calcium can enter the cell, e.g., through calcium channels.

The fact that aminoglycosides interact with hair cells can be deduced from the displacement of calcium and was also demonstrated directly. It is noteworthy that the binding of gentamicin was observed in a physiological medium (HBSS) containing not only high levels of monovalent cations but also $>1 \mathrm{mM}$ calcium and magnesium, a $>10000$-fold molar excess over gentamycin. This indicates the high affinity of the drug for the hair cells. 
Gentamicin appears to be bound at more than one sitc. The existence of two pools of this drug is suggested by the displacement of only $61 \%$ of the labeled gentamicin by a post-incubation 'wash' with a 10000-fold excess of unlabeled drug. The remaining $39 \%$ must be considered sequestered in a non-exchangeable pool. This finding is not only qualitatively but also quantitatively similar to the documentation of two gentamicin pools in the crista ampullaris (Williams et al., 1987).

While one of the binding sites may be at the plasma membrane (exchangeable) the other may be intracellular. Uptake of gentamicin by an active transport process was originally concluded from our studies in the crista ampullaris. The present observation that elimination of metabolic activity by cooling the hair cells led to a drastic reduction of their gentamicin content is compatible with this notion. An energy-dependent uptake but not external binding or diffusion should he temperature-dependent in such a fashion.

Both neomycin and spermine share the same binding sites or uptake mechanisms as indicated by their competition with gentamicin. For neomycin this may be an obvious expectation as aminoglycosides have most of their biochemical and pathophysiological actions in common. The competition with the polyamine spermine again agrees with the characteristics of gentamicin uptake established in the crista ampullaris (Williams et al., 1987). In analogy, it suggests that aminoglycosides may, at least in part, utilize polyamine transport systems for cellular uptake. This may answer the question why, in hair cells, an active uptake exists for a non-physiological compound such as gentamicin.

The labeling of phospholipids in isolated hair cells by $\left[{ }^{32} \mathrm{P}\right]$ orthophosphate attests to the viability of the cells in vitro. As in the case of gentamicin uptake, ${ }^{32} \mathrm{P}$-labeling of lipids requires metabolic activity. The [ ${ }^{32} \mathrm{P}$ ]orthophosphate first is incorporated into ATP by oxidative phosphorylation in the mitochondria. Subsequently $\left[{ }^{32}\right.$ P]ATP donates its labeled phosphate in several sequential reactions to the phospholipids.

The chromatography of these labeled lipids on gentamicin demonstrates that the aminoglycoside recognizes $\mathrm{PIP}_{2}$ and binds to it with a high and specific affinity. This is seen by the need for an extreme concentration of salt $(600 \mathrm{mM})$ to displace the bound lipid from the drug quite in contrast to the other anionic phospholipids. This is similar behavior to that exhihited by phosphoinositides from renal and cochlear tissues when chromatographed on immobilized neomycin (Schacht, 1979) and supports the idea that PIP is a preferred aminoglycoside binding site in outer hair cells. In view of the importance of $\mathrm{PIP}_{2}$ in cellular physiology (Berridge and Irvine, 1984; Schacht and Zenner, 1986) this drug/lipid interaction may have crucial consequences for the function of the hair cell. The binding by an aminoglycoside will prevent the hydrolysis of $\mathrm{PIP}_{2}$ (Schacht, 1976; Van Rooijen and Agranoff, 1985) and thus the formation of the second messenger, inositol trisphosphate. Consequently, the physiological role of the phosphoinositide cascade is compromised (Fig. 3). Since this is an attack on an

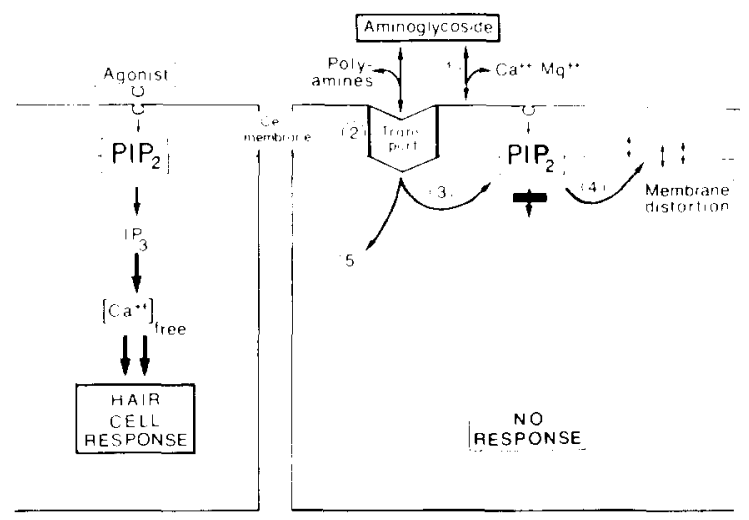

NORMAL CELL

AMINOGLYCOSIDE ACTION

Fig. 3. Molecular mechanism of aminoglycoside toxicity. (Right) The toxic actions of the drugs encompass several sequential steps. (1) Binding to the plasma membrane and displacement of cations such as calcium. This step should acutely but reversibly interfere with calcium-dependent membrane functions. (2) Uptake into the cell. This process is suggested to be energy-dependent and competitive with polyamine transport. (3) Binding to $\mathrm{PIP}_{2}$ on the cytoplasmic side of the membrane. As a consequence, the physiological function of $\mathrm{PIP}_{2}$ is inhibited and the integrity of the plasma membrane disrupted (Au et al., 1986a, b). Further intracellular actions of the drug may ensue. (Left) The physiological role of $\mathrm{PIP}_{2}$ in outer hair cells (Schacht and Zenner, 1986). The phosphoinositide second messenger system may mediate motility. The stimulus (presumably the efferent input) activates the formation of the second messenger $I P_{3}$ (inositol trisphosphate) from $\mathrm{PIP}_{2} . \mathrm{IP}_{3}$ liberates calcium from intracellular stores and the elevated calcium levels in turn trigger the response of the cytoskeletal contractile system. 
amplification mechanism the elimination of even a few molecules of this messenger by low concentrations of the drug should cause a severe impairment of cellular functions.

The results presented here considerably strengthen our hypothesis of the molecular mechanisms of aminoglycoside ototoxicity since cochlear damage by gentamicin (used here as a representative cochleotoxic aminoglycoside) is primarily expressed in outer hair cells. Furthermore, our studies have shown that biochemical investigations of outer hair cells in vitro are feasible. While the sensitivity of current methods and the lack of availability of large quantities of hair cells may place some limits on the studies possible, it is clear that important questions of molecular pathology and physiology of hair cells can be directly approached.

\section{Acknowledgements}

The authors thank Gary Zajic for providing the photos in Fig. 1. This research was supported by research grant no. NS-13792 from the National Institutes of Health and a grant from the Deutsche Forschungsgemeinschaft.

\section{References}

Au, S., Schacht, J. and Weiner, N.D. (1986a) Membrane effects of aminoglycoside antibiotics measured in liposomes containing the fluorescent probe, 1-anilino-8-naphthalene sulfonate. Biochim. Biophys. Acta 862, 205-210.

Au, S., Weiner, N.D. and Schacht, J. (1986b) Membrane perturbation by aminoglycosides as a simple screen of their toxicity, Antimicrob. Agents Chemother. 30, 395-397.

Berridge, M.J. and Irvine, R.F. (1984) Inositol trisphosphate, a novel second messenger in cellular signal transduction. Nature 312, 315-321.

Brownell, W.E., Bader, C.R., Bertrand, D. and Ribeaupierre, Y. (1985) Evoked mechanical responses of isolated cochlear outer hair cells. Science 227, 194-196

Flock, A., Flock, B. and Ulfendahl, M. (1986) Mechanism of movement in outer hair cells and a possible structural basis. Arch Oto-Rhino-Laryngol. 243, 83-90.

Hawkins, J.E. Jr. (1976) Drug ototoxicity. In: Handbook of Sensory Physiology, Vol. 3, pp. 707-748. Editors: W.D. Keidel and W.D. Neff. Springer-Verlag, Berlin.

Hudspeth, A.J. (1985) The cellular basis of hearing: The biophysics of hair cells. Science 230, 745-752.

Lodhi, S., Weiner, N.D. and Schacht, J. (1979) Interactions of neomycin with monomolecular films of polyphosphoinositides and other lipids. Biochim. Biophys. Acta 557, 1-8.
Orsulakova, A., Stockhorst, E. and Schacht, J. (1976) Effect of neomycin on phosphoinositide labeling and calcium binding in guinea pig inner ear tissues in vivo and in vitro, $J$ Neurochem. 26, 285-290.

Schacht, J. (1976) Inhibition by neomycin of polyphosphoinositide turnover in subcellular fractions of guinea pig cerebral cortex in vitro. I. Neurochem. 27, 1119-1124.

Schacht, J. (1978) Purification of polyphosphoinositides by chromatography on immobilized neomycin. J. Lipid Res. 19, 1063-1067.

Schacht. J. (1979) Isolation of an aminoglycoside receptor from guinea pig inner ear tissues and kidney. Arch. Oto-RhinoLaryngol. 224, $129-134$.

Schacht, J. (1986) Molecular mechanisms of drug-induced hearing loss. Hear. Res. 22, 297-304

Schacht, J. and Van De Water, T. (1986) Uptake and accumulation of gentamicin in the developing inner ear of the mouse in vitro. Biochem. Pharmacol. 35, 2843-2844.

Schacht, J, and Zenner, H.P. (1986) The phosphoinositide cascade in isolated outer hair cells: possible role as second messenger for motile responses. Hear. Res. 22, 94

Tachibana, M., Anniko, M. and Schacht, J. (1983) Effects of perilymphatically perfused gentamicin on microphonic potential, lipid labeling, and morphology of cochlear tissues. Acta Oto-Laryngol. 96, 31-38.

Takada, A. and Schacht, J. (1982) Calcium antagonism and reversibility of gentamicin-induced loss of cochlear microphonics in the guinea pig. Hear. Res. 8, 179-186.

Takada, A., Bledsoe, S. and Schacht, J. (1985) An energy-dependent step in aminoglycoside ototoxicity: Prevention of gentamicin ototoxicity during reduced endolymphatic potential. Hear. Res. 19, 245-251.

Tran Ba Huy, P., Bernard, P. and Schacht, J. (1986) Kinetics of gentamicin uptake and release in the rat: Comparison of inner ear tissues and fluids with other organs. 3. Clin. Invest. 77, 1492-1500.

Van Rooijen, L.A.A. and Agranoff, B.W. (1985) Inhibition of polyphosphoinositide phosphodiesterase by aminoglycoside antibiotics. Neurochem. Res. 10, 1019-1024.

Wang, B.M., Weiner, N.D., Takada, A. and Schacht, J. (1984a) Characterization of aminoglycoside-lipid interactions and development of a refined model for ototoxicity testing. Biochem. Pharmacol. 33, 3257-3262.

Wang, B.M., Weiner, N.D., Ganesan, M.G. and Schacht, J. (1984b) Interaction of calcium and neomycin with anionic phospholipid-lecithin liposomes: A differential scanning calorimetry study. Biochem. Pharmacol. 33, 3787-3791.

Williams, S., Smith, D.E. and Schacht, J. (1987) Characteristics of gentamicin uptake in the isolated crista ampullaris of the inner ear of the guinea pig. Biochem. Pharmacol. 36, 89-95.

Zajic, G. and Schacht, J. (1987) Comparison of isolated outer hair cells from five mammalian species. Hear, Res. 26. $249-256$.

Zenner, H.P. (1986) Motile responses in outer hair cells. Hear. Res. 22, 83-90.

Zenner, H.P., Zimmermann, U. and Schmitt, U. (1985) Reversible contraction of mammalian cochlear hair cells. Hear. Res. 18, 127-133. 